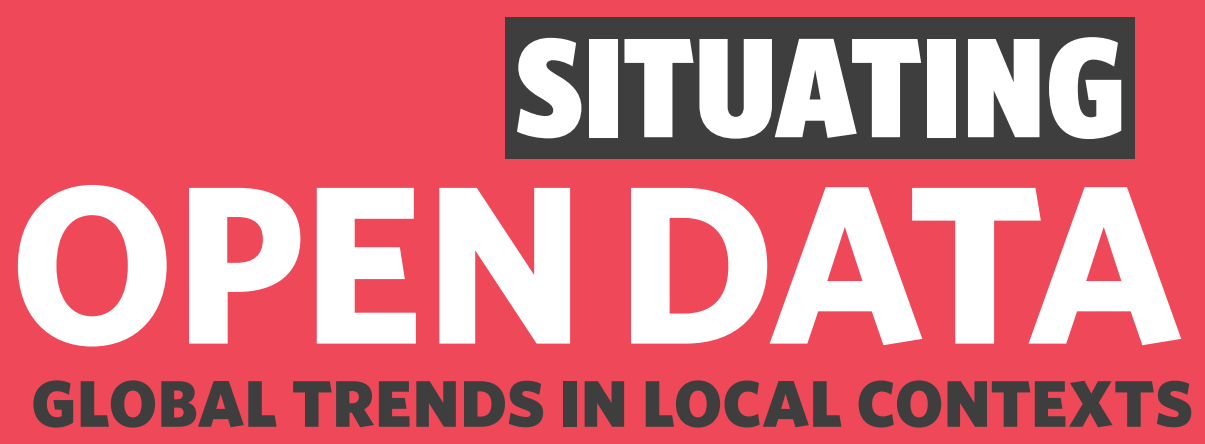

Edited by Danny Lämmerhirt, Ana Brandusescu, Natalia Domagala \& Patrick Enaholo 


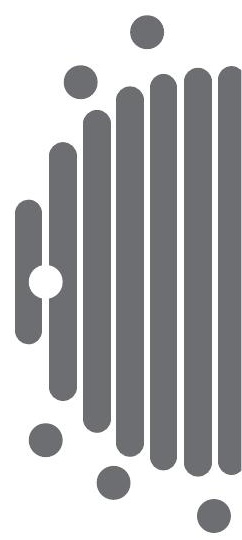

\section{Situating Open Data Global Trends in Local Contexts}

Edited by

Danny Lämmerhirt, Ana Brandusescu, Natalia Domagala \& Patrick Enaholo 
Published in 2020 by African Minds

4 Eccleston Place, Somerset West 7130, Cape Town, South Africa

info@africanminds.org.za

www.africanminds.org.za

This work is published under a Creative Commons Attribution 4.0 International License (CC-BY).

ISBN Paper 978-1-928502-12-8

ISBN eBook 978-1-928502-13-5

ISBN ePub 978-1-928502-14-2

Orders:

African Minds

4 Eccleston Place, Somerset West 7130, Cape Town, South Africa

info@africanminds.org.za

www.africanminds.org.za

For orders from outside South Africa:

African Books Collective

PO Box 721, Oxford OX1 9EN, UK

orders@africanbookscollective.com

www.africanbookscollective.com 


\title{
Connecting flows and places: Flows of (open) data to, from and within hyperlocal communities in Tanzania
}

\author{
François van Schalkwyk
}

This chapter presents findings from research on the flow of data in the United Republic of Tanzania, and specifically on the flow of data to and from the hyperlocal level in the health system of that country. The research was undertaken to provide open data initiatives wishing to stimulate the evolution of a data system with empirically-based evidence on the blockages, breaks and connectors in the flow of data in such systems, as well as the possible role of open data in creating new flows to communities at the hyperlocal level.

\section{Understanding data flows in Africa}

African countries have pledged to achieve sustainable development and inclusive grow th by adopting the 2030 Agenda for Sustainable Development and the Agenda 2063. At the national level, this can be seen in long-term national development plans and numerous legal, legislative and policy reforms aimed at improving the quality, timeliness, relevance, availability and accessibility of data. At the time of writing, Ethiopia, Ghana, Mauritius, Rwanda, Sierra Leone, Tanzania and Tunisia had published data policies, or were in the process of doing so, and there were at least 12 separate national government-led open data initiatives on the continent. But data alone is not enough to drive development - equally important are the actors, infrastructures, technologies and emergent social dynamics, including the distribution of power, that shape the flow of data, in so doing connecting data to the policy- and decision-makers instrumental in the allocation and distribution of resources in pursuit of equitable human development.

To illustrate, data are routinely collected at the local level by local governments across the globe. These data are fed into state, national or federal management 
information systems for planning purposes which ultimately provide the basis for determining the distribution of resources (political agendas and corrupt practices notwithstanding). At the same time, data feed indicators of a nation's financial health, including, for example, its economic growth and the investment climate which, in turn, rely on data describing the social conditions and wellbeing of defined populations. This is vital data that, when circulating in global financial networks, determines the ability of the state to access (and provide) financial instruments in the globalised financial system. This is not only about access to global financial networks, but about nation states becoming inexorably integrated into the global financial system. According to Castells (2017), three major processes are changing the coordinates of the global political economy, one of which is that global financial markets are increasingly the core of national and international economies.

However, the primary data and those who inhabit the local spaces from which primary data originate, typically remain disconnected (Mori et al. 2014; Wickremasinghe et al. 2016) from decision-making. Custer et al. (2018) argue that improvements in sub-national data collection will bring data closer to place-based decision-making. According to Castells $(2009,2010)$ the internet and communication technologies that have been developed to exploit real-time connectivity on a global scale have had profound effects on society. This is most evident in how society is being reorganised according to the programmes of global networks and the effects of this restructuring on the development of society (Castells \& Himanen 2014). There are legitimate concerns that, rather than making possible a more equitable distribution of resources, the network society is one in which exclusion is structurally manifest and the gap between the rich and the poor, the powerful and the marginalised, the metropolitan and rural, is certain to widen (Castells \& Himanen 2014; Ravallion 2016).

At the risk of oversimplification, Castells (2010) explains this structural binary divide as being attributable to a particular condition of the network society: the cleavage between two spaces - the space of flows and the space of places. The space of flows describes that placeless space where information is exchanged in real-time across global networks. The space of places describes the local, physical spaces in which social actors live and breathe; where they seek meaning and define who they are. The disconnect between these two spaces in the network society provides a useful framework for understanding the breakages and asymmetries in the flow of data between local communities, their governments and global networks. The approach also offers a more nuanced account of the contingent relationship between data and the spaces in which data are situated at any given time.

Open data could play a role in ameliorating the exclusionary effects of networks by democratising access and the use of data as a highly prized commodity in global networks (Van Schalkwyk \& Cañares 2020). More equitable access, in turn, makes possible, in theory at least, the reprogramming of networks 
by certain strategically located actors in networks, that is, switchers and programmers (Castells 2009, 2010). Switchers connect networks, programmers set the overarching logic of the network. In plain terms, open data can mobilise social movements to effect change in networks programmed according to logics that will not deliver equal and sustainable societal benefits. Governments themselves, as programmers, may take the lead to leverage open data for more equitable outcomes. In the health sector, for example, governments in various parts of the world are seeking to unlock the potential of open data to improve the quality of care, lower healthcare costs and facilitate patient choice (Scrollini 2017; Van Schalkwyk et al. 2017; Verhulst et al. 2014).

To conclude, there remains a lacuna when it comes to an understanding of the flows of data, particularly as it relates to the local level. This research therefore poses two questions: 'How does data flow in a specific data system?' and 'What is the contribution of open data in stimulating data flows in the data system?'

\section{Analysing data flows}

Data flows are best understood with reference to the movement and exchange of raw and processed data between humans and machines in complex sociotechnical systems. This approach is consistent with those adopted by others (see, for example, Bates et al. 2016; Kitchin \& Lauriault 2014) in its attempt to illuminate 'the concrete ways in which evolving socio-cultural values and material factors cohere over time to create the socio-material conditions that frame activities of data production, processing and distribution and resultantly influence the form and use of data' (Bates et al. 2016).

In this chapter, the use of data flows is preferred to 'data journeys' as proposed by Bates et al. (2016). This is because the notion of a journey implies a degree of agency to data, a purpose. While it is true that data is not necessarily neutral and is subject to manipulation which, in turn, can have profound effects on decisionmaking, both its neutrality and its purpose are compromised and determined by the actions of humans (or possibly machines). Data has no inherent volition or velocity; data are socially constituted and its emergent materiality is socially dependent and technologically enabled. Furthermore, the concept of flows, like journeys, does convey important properties; properties that indicate how data moves through complex socio-technical systems. Flows may be rapid, slow or non-existent (Van Schalkwyk et al. 2016); flows may be channelled, redirected or divided; and flows may be fragmented, partial or disconnected within and between systems.

Data flows imply a flow between, from one point in time and space to another point. The situatedness and movement of data has led scholars to draw attention to the importance of data infrastructures (Dodds \& Wells 2019). Rather than existing in isolation, data infrastructures are connected and arranged into data assemblages (Kitchin \& Lauriault 2014). Assemblages shape data and their 
flows are, in turn, shaped by both the data and their socio-materiality (Bates et al. 2016; Kitchin \& Lauriault 2014). The limitation of data assemblages is that while the approach acknowledges the social contingency of any assemblage, it tends towards a focus on connections within assemblages at the expense of connections between assemblages in broader networks as well as the connections between those networks. As a consequence, the effects of 'meta-assemblages' and, more importantly, of global networks acting on one another is lost.

This limitation is illustrated by the often-used analogy of data infrastructures resembling road networks (see, for example, Dodds \& Wells 2019). The rules of the road are typically defined at the national rather than the global level; while roads connect physically across national borders, it is not possible to connect across large bodies of water and there is competition for road space resulting in traffic congestion. Data does not have to contend with these impediments by virtue of its non-rivalrous, digital nature and a global, fully interconnected network (the internet) for its movement.

The arrangement of actors and the dynamic conditions in which data production, processing, distribution and use occur, have led other scholars to refer to assemblages as 'ecosystems' (Harrison et al. 2012; Heimstädt et al. 2014; Van Schalkwyk et al. 2016). Ecosystems consist of mutually interacting organisms; are complex in their arrangement; characterised by the interdependency of and between organisms and resources; are dynamic rather than static (seeking equilibrium through motion rather than stasis); populated by keystone species that play a critical role in facilitating exchange in the ecosystem thereby ensuring dynamism and constant movement; movement tends to be cyclical and reinforcing, making the system resilient (adaptable and restorative) but ecosystems are also vulnerable to exogenous forces which may disrupt or destroy the ecosystem (Van Schalkwyk et al. 2016).

While both data assemblages and ecosystems are clearly complex, they can be mapped by identifying the components of the system and the relationships between those components. Components include human and non-human agents, as well as the routines, rules and norms that emerge from their interaction.

The benefit of the ecosystem approach is that it fits more comfortably with a network understanding of society as described in the introductory section to this chapter. A network approach situates data, its assemblages and flows within a broader socio-political framework that accounts for the social forces that act upon data. The approach brings to the surface not only an understanding of the component parts, movement and endogenous forces acting on data within assemblages but also of the exogenous and divergent social forces that shape those assemblages. Such an understanding can account for friction in the flows of data (Bates et al. 2016) between those operating in global networks and those local communities external to those networks as distinctive sites of practice subject to different logics or programmes. Kitchin and Lauriault (2014: n.p.) write that 'databases and repositories are expressions of knowledge/power, shaping what 
questions can be asked, how they are asked, how they are answered, how the answers are deployed, and who can ask them'. An acknowledgement of the inescapable effects of how power is distributed and exercised in socio-technical systems (or networks) is critical; the data flows approach adopted in this chapter accounts for such power dynamics but takes the analysis beyond databases and repositories into the complexity of a networked social world defined, in part, by the cleavage between non-material spaces of flows and the local place-based spaces inhabited by local communities.

\section{Methods}

The approach of this study is informed by and consistent with critical data studies, that is, studies that seek to develop critical, qualitative methodologies to enhance our understanding of the place of data in society (Kitchin \& Lauriault 2014). It also seeks to contribute to previous empirical studies on the subject, for which there remains a need (Bates et al. 2016).

This research formed part of the Data Zetu ${ }^{1}$ project which sought to amplify citizens' voices through data. The Data Zetu project was located in Tanzania and was funded and implemented in partnership by the United States President's Emergency Plan for AIDS Relief (PEPFAR) and the Millennium Challenge Corporation (MCC) as part of the Data Collaboratives for Local Impact programme (DCLI). ${ }^{2}$ The scope of the research was therefore defined by the activities of the project, both in terms of sectors and geography.

From the regions in which the project was active, four wards in the Kyela district in the Mbeya region located in south-western Tanzania were selected as the study site. Selection was based on the remoteness of the district from any urban centres more likely to be connected to global networks and by the degree of access to key informants in the districts. The wards in Kyela district constitute the hyperlocal level in this context; adding a more fine-grained level of analysis to those typically used (i.e. supranational, national and sub-national).

Information on the available datasets in the ecosystem was collected in the first instance by means of desk research and in consultation with the Tanzania Data Lab (dLab) as it works closely with both the national bureau of statistics (NBS) and civil society organisations (CSOs) in the health sector in Tanzania. By conducting interviews, searching the media and consulting other data mapping efforts, 37 health-related data sources were identified and coded for: name (of the dataset); collection type (e.g. database; dashboard; document repository); types of data (e.g. health; demographics; education); keywords (describing the data, e.g. mortality, malaria, TB); collection (method of collecting the data, e.g. routine, survey, third-party); data owners (primary = owner of the source

1 https://datazetu.or.tz/

2 https://www.mcc.gov/initiatives/initiative/mcc-pepfar-partnership 
data; secondary $=$ owner or host of the platform or medium for accessing the data); data source (from whom is the data collected, e.g. district office, general population, health facility); level (e.g. supranational, national, regional); formats (e.g. excel, PDF, csv); most recent data available (year); available online (yes/no); accessible (yes/no); open data (yes/no) and URL (to dataset or to page where data can be found). This list was not meant to be exhaustive but rather to represent a sample of the types of Tanzanian health data available and, important in the context of this study, the levels at which the data are made available.

Once the identification of health datasets was complete, the flow of data was traced from the local to the national and/or supranational levels and vice versa, using the list of data sources. Further unstructured, in-person interviews conducted in December 2017 and March 2018 verified mapped flows, identified data and data sources previously not identified and provided insights into context-specific data practices.

To map more precisely data flows and practice at the hyperlocal level, fieldwork was conducted in Kyela district in August 2018. A structured questionnaire was administered to government health facility supervisors at 31 health facilities in the Kyela district, to the district executive director and to the district medical officer (DMO). The data were captured in a quick-tap survey application using hand-held devices and exported to Microsoft Excel for cleaning and analysis.

\section{Findings}

The findings of the data flow mapping exercise for the health data in Tanzania is presented graphically in Figure 1 . The ministry of health $(\mathrm{MH})$ is located at the top of the diagram and represents the national level at which health data is integrated, controlled and analysed. At the bottom of the diagram is the hyperlocal level, represented in this case by the communities and health facilities of Kyela district. On each side of the diagram are the other actors identified in the data system, loosely grouped into CSOs to the bottom left and research organisations to the bottom right of the diagram.

In the sections that follow, the flow of data in the system is discussed. It is acknowledged that mapping a complex system graphically will always fall short of the reality which it attempts to represent. Nevertheless, it is hoped that even an oversimplified representation of reality can provide some useful insights into how data flows in the health data system in Tanzania.

\section{Vertical data flows from the hyperlocal level to the national level}

Vertical data flows describe top-down and bottom-up flows. In this section, the focus is on bottom-up flows, that is, from the hyperlocal level to the national level. A later section deals with return or top-down flows. 
Figure 1 shows that at the most granular level, health data is collected at health facilities located in districts. All public and private health facilities (hospitals, dispensaries, clinics and health centres) capture patient and operational data and submit these to the district medical officer's (DMO) office. Data on deaths, births, outpatients, inpatients, ante- and postnatal care, vaccinations and HIV/Aids treatment are just some of the data types that must be collected at the facility level.

Much of the data capturing is still done in paper format using prescribed printed forms provided by the MH. Data are captured in counter books before being transcribed to the MH's standardised forms. It was found that $19 \%$ of health facilities capture data only in paper format with the remaining $81 \%$ using both paper and electronic data capturing methods. Data are typically converted into electronic format for submission to the DMO, although some still submit data to the DMO only in paper format. This finding confirms previous research that reported that as much as $30 \%$ of facility-level data is submitted to the district medical office in paper format (Bhatia et al. 2016).

At the DMO, health facilities data are captured in the central health management information system software, the District Health Information System (dhis2), ${ }^{3}$ by DMO office staff. This constitutes a second instance of data capturing.

In addition to health data received from health facilities, DMOs capture in dhis2 other data specific to their district (e.g. demographic data). These data are required for the production of health indicators for monitoring and evaluation purposes at the district level and are sourced from other government departments and agencies such as the national bureau of statistics. It was not established how officials in the DMO's office access and capture non-health data obtained from NBS.

Data on health commodities (i.e. medicines) are captured in the national electronic logistics management information system (eLMIS) and not in dhis2. In Tanzania, the eLMIS collects data from more than 6000 service delivery points (USAID 2015). Dhis2 is linked to eLMIS and extracts selected data from that database (e.g. on tracer medicines) to produce certain health indicators. More than one interviewee commented that while the design of the eLMIS system looks good on paper, there are concerns about the comprehensiveness and quality of the data captured in eLMIS.

CSOs and other project-based initiates also participate in the collection of routine data at health facilities. These data are also sent to the DMO for capturing into dhis2. CSOs are therefore active participants in the health data system but do not capture health data directly into any of the central health data systems administered by the government.

3 DHIS2 (District Health Information System) is used in more than 60 countries and is an open source software platform for reporting, analysis and dissemination of data for all health programmes, developed by the Health Information Systems Programme. 
Findings show that data do not flow from non-facility sources such as health surveillance sites or outposts to dhis2. Nor are survey or surveillance sentinel data captured in the dhis 2 system, either via the DMO or from the National Health Institute for Medical Research or Ifakara Health Institute, the latter being the corner-stone institution for government health research.

Survey data are also collected at the population level in the form of population-based surveys such as the Demographic and Health Survey and the HIV/Aids and Malaria Indicator Survey conducted by the national bureau of statistics; the Population and Housing Census also conducted by NBS; the Demographic Surveillance System, which monitors vital statistics at sentinel sites located at various regions in the country; sample vital registration with verbal autopsy, which operates under the sentinel panel of districts and national vital registration systems and other specific health and health-related research works. Results from surveys are typically presented in report-format to $\mathrm{MH}$ and other interested government officials.

Therefore, any medical or health-related event that occurs within communities, and does not involve a health facility, will not be captured in dhis2. Such data are not included in any analysis done using dhis 2 data, be it by the $\mathrm{MH}$, the President's Office Regional Administration and Local Government offices (PORALG) or the Council Health Management Teams (see below for more detail).

According to a DMO, the '[District Executive] accepted that village leaders can provide accurate data [when] we were distributing nets. They have been insufficient all the time due to underestimating population. After realizing that, we have been working with village leaders in identifying children under five and mothers. This information is always exact' (Bhatia et al. 2016: 12). In this case the medical officer is pointing out the problems of relying on inaccurate population data from the national level when distributing mosquito nets and that the community is able to provide more reliable data to ensure more effective intervention. However, mechanisms for connecting village leaders to health workers are non-functional and therefore do not facilitate the flow of data into the national health system via local health facilities (see also Silaa \& Van Schalkwyk 2018).

The mHealth Tanzania Public-Private Partnership is an initiative that makes possible upward flows from isolated or disconnected health workers. The Partnership focuses on addressing ministry-defined public health priorities by supporting solutions that work in concert with initiatives underway at the MH. mHealth initiatives include those that provide direct health communications to citizens via SMS and clinical decision information and reminder services for health workers. These services rely on existing data held by the MH. But health data is also captured by mHealth initiatives by, for example, the Infectious Disease Reporting System (IDRS) which allows health-facility workers to report disease surveillance data by making a free call from the field using any mobile phone. Real-time SMS and email alerts are then generated by the system for follow-up and action. 
Horizontal data flows describe those data flows between actors operating at the same level in the data ecosystem. Figure 1 shows intra-governmental data flows between $\mathrm{MH}$ and the NBS as well as the flows within divisions of $\mathrm{MH}$.

Data flows from NBS to $\mathrm{MH}$ are either by request (usually for microdata) or by presentation (aggregated summary data), typically following the completion of one of the national surveys. Data are presented by NBS as aggregated data and indicators in reports made available in print and PDF formats. Data requests are usually activated and responded to at a high level across government agencies. For example, data requests to NBS often originate in parliament. In such cases, data requests are made by the permanent secretary in the President's Office to the Director of NBS.

Data flows within $\mathrm{MH}$ show evidence of increased levels of coordination and integration. For example, collection of HIV/Aids data has been integrated into dhis2. According to the National Aids Control Programme's 'National Guidelines on HIV and Aids Data Management' report, data is collected at facility-level using the CTC2 database and dhis2 is the main repository for HIV and Aids data (MOHCDGEC 2017). Aggregated quarterly reports from CTC2 are captured in dhis2 while granular patient data remains in the CTC2 system. The HIV/Aids client records database has scaled to more than 900 facilities, improving record keeping for tracking of HIV/Aids clients (PATH 2017). The TB/Polio database remains separate but shares architecture with dhis2. The eLMIS database also remains separate from dhis2, but dhis 2 draws on data from that database in order to produce key health indicators.

Return, vertical data flows: National level to hyperlocal level

According to the World Health Organization (WHO):

Access to health information [in Tanzania] for all levels from the general community up to decision-makers, and the utilisation of the generated health information, have been inadequate and this is a major challenge to the health system. There are no standardised methodologies in place to ensure appropriate information is channeled to the right person at the right time and for the right purpose. Thus, there has been poor utilisation of the available information for knowledge strengthening and supportive evidence for decision-making. (n.d.)

District-level health management teams have access to dhis 2 data and these data are accessed via reports generated by the dhis 2 system. Bhatia et al. (2016) report, however, that analysis and planning at the district level cannot rely on dhis 2 data alone and requires deeper analysis. The fact that community and 
other data sources are not available to district officials may hamper such analysis. For example, data from sentinel surveillance (including local data on births, deaths and burden of disease) are not used to calibrate and validate findings from facility-based data. And the fact that dhis 2 does not include districtspecific indicators (i.e. indicators relevant to specific district health needs and not included in the dhis 2 indicators that are determined by national priorities), places further constraints on the availability and use of fine-grained, contextspecific health data. A case in point in Kyela district are the seasonal cholera outbreaks that are not prioritised to the same extent as HIV/Aids and TB at the national and supranational levels. Data on cholera outbreaks are collected by several health facilities in Kyela district but there are no indicators for cholera on the national portals (Silaa \& Van Schalkwyk 2018).

Communities do not have any direct access to health data held by facilities nor do they have indirect access via intermediaries such as faith-based organisations or CSOs.

\section{Horizontal data flows: hyperlocal level}

All dhis2 district-level health data is centralised by the District Medical Office and health commodities data is centralised by the national Medicine Stores Department. While they are the primary source of the national government's health data, health facilities can only access their own data on the national health management information system (dhis2) and on other relevant systems (such as eLMIS). They are therefore unable to access electronically the health data collected by neighbouring health facilities in the same district.

Limited horizontal access to health data at the facility level should not be interpreted as a lack of information sharing: 29 (90\%) of facilities indicated that they are able to access health data from other facilities. Of those 29 health facilities, $94 \%$ indicated that they request data by telephone. In most cases $(65 \%)$ requests are made only by telephone while in other instances, telephone calls are combined with a visit to the facility $(10 \%)$ or with sending a WhatsApp message (19\%). A small number of respondents (6\%) indicated they make exclusive use of WhatsApp to request data from other health facilities. Limited, informal data sharing takes place in the absence of formal mechanisms to facilitate data sharing.

Research has also shown that CSOs are not publishing or sharing their health-related data (Tunga \& Mushi 2016) with other actors in the health system and this was confirmed in the interviews conducted. The sharing of health data among CSOs and between CSOs and the general public is poor. Mostly, data are used internally to produce reports, briefs and other outputs in support of advocacy work. Consequently, data is shared by disseminating printed materials or by making presentations to relevant stakeholders. 
Figure 1. Data flows in the Tanzania health system

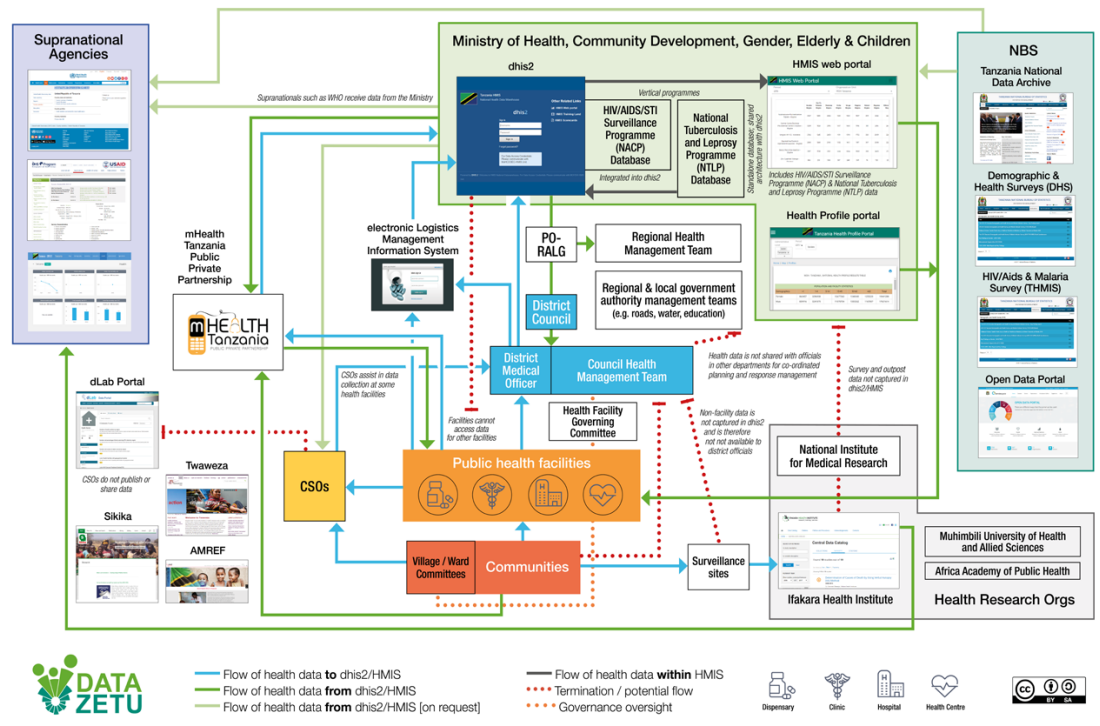

Feedback loops, data quality and terminations

In its 2018 policy, the MH states that the objectives for establishing a monitoring and evaluation system for the health sector in Tanzania include:

- Providing a mechanism for feedback to update the information system;

- Providing reports to all stakeholders with necessary and sufficient data (MOHCDGEC 2018).

Figure 1 shows that only one feedback loop is in operation - the supply of facility data by the district medical office to dhis 2 and the use of the same data by district health planning officials, including the Council Health Management Team, for planning, response and resource allocation to facilities that provided the data.

Feedback loops are organic, social arrangements that depend on sanctions or rewards to operate. Sanctions assume the form of either explicit rules or institutionalised norms. Rewards exist in the form of incentives for the initiator of the feedback loop and for all subsequent data contributors and users. Incentives may be either material or non-material. Findings suggest that health officials at the facility level are motivated to submit health data on time, most likely because timely submission is a key indicator in their performance evaluations. Their motivation therefore appears to be driven by the threat of sanctions rather than on incentives that could, for example, be linked to the quality of the data submitted (see also Bhatia et al. 2016; Sato et al. 2017). On this basis, upward 
flows appear to be efficiency- rather than quality-driven and this has serious implications for the usefulness of the data for planning and resource allocation in return downward flows of health data in Tanzania.

Interviewees expressed concerns about the quality of the data transcribed as transcription is often done by nurses or administrators with poor data skills who are under pressure to submit the data on time. Kimunai (n.d.) reports that some health facility staff would ask those with data skills to capture data on their behalf because they lack the skills to do so. 'Data cooking' was cited by one interviewee as being common, as data capturers make up data to compensate for data gaps in the health facilities' records. Sato et al. (2017) measured aspects of motivation among health workers in rural Tanzania and found that having a clear job description is the greatest motivation for health workers in executing their functions. It follows that if nurses and other health workers whose description does not include data transcription and capturing for reporting purposes (as opposed for patient management) are expected to undertake these data-related functions, then their motivation for completing these functions accurately, will be low.

Dhis2 officials indicated that data quality tools have been made available to health officials to check the quality of the data submitted to and by the DMO and that the $\mathrm{MH}$ has been rolling out data training at the facility level to improve skills and capacity in data capturing. At the DMO, a Health Management Information System (HMIS) coordinator validates the data in the system based on observed data anomalies in which case the health facility is contacted for verification. However, respondents indicated that corrected data may or may not be updated in dhis 2 because after data submission deadline, making changes to the data in the system raises 'a lot of issues'. The implication of this reluctance to update incorrect data is that the correct data will be held at the DMO but will not be in dhis2. It was also indicated that some data go through more thorough checking processes because donor funding is available. This means that some types of health data (e.g. HIV-related data) receive more attention based on the funding priorities of supranational donors.

While training may help to prevent errors and tools may flag obvious data errors, it is not clear how manufactured data can be prevented and detected when the incentives for accurate data collection and for capturing corrections are absent at the hyperlocal level. This raises serious concerns about the quality of the data in dhis 2 used to conduct modelling, analysis and, ultimately, to make decisions about the allocation of health resources.

In many other instances, Figure 1 shows terminations in the flow of data, thus precluding the creation of feedback loops. Boerma (2013) argues that districts require health information systems that draw from multiple sources. To some extent, integration of data sources has taken place at the national level, but non-facility health data from surveillance sites, from the community and from CSOs do not flow into the health information system. Thus, there is no 
formalised system for DMOs and health teams to access non-facility health data. And, as a consequence, there are no systematic local feedback loops between health officials and these sources of health data. As decentralisation in Tanzania continues, local decision-makers will have more opportunities to use results data for local decisions.

At the same time, CSOs are either loath or ill-equipped to share health data. Findings show that research institutes appear more inclined to share data with international donors than with either the national health ministry or local health officials. Health facilities in the districts are not able to access each other's administrative and performance data via dhis 2 . If they were able to do so, this could improve district-level coordination in cooperation with the DMO and other stakeholders active at the hyperlocal level.

\section{Open data}

Several sources of open health data are available in the Tanzania health data system, although they vary in the extent to which they meet some of characteristics often prescribed for open data such as being published under an open license, being machine readable and being available in bulk. Nevertheless, these datasets are all online and accessible without restriction.

Open data made available by the government comes from three main sources. The first is data published by the MH predominantly from its health management information system, dhis 2 , on two publicly accessible data portals: (1) the HMIS web portal ${ }^{4}$ and (2) the Health Profile portal. ${ }^{5}$ The HMIS portal makes available indicator and raw data primarily on diseases but also includes demographic data (e.g. population by age), data on health personnel (e.g. health workers by cadre) and the completeness of health data collection across the system. The HMIS portal includes data from two non-facility sources: the HIV/ Aids/STI Surveillance Program (NACP) and the National Tuberculosis and Leprosy Program (NTLP). The NACP's data has been integrated into the dhis 2 while the NTLP remains a separate database from which dhis 2 extracts relevant data for producing indicators. The Health Profile portal's focus is on data and indicators related to health service delivery, including resourcing, medicines and infrastructure. Both publish data disaggregated to the district level.

The second source of open data is from the NBS. Data is published on the Tanzania National Data Archive and includes data from the health-related surveys conducted by NBS. The Tanzania Open Data Portal also falls under NBS and contains 12 health-related datasets mostly uploaded by the $\mathrm{MH}$.

A third source of open health data is the data published by the Ifakara Health Institute. At the time of writing only 8 of 109 datasets listed in its central data

4 https://hmisportal.moh.go.tz/hmisportal/\#/

5 https://hmisportal.moh.go.tz/dhpportal/\#/home 
repository were either available as 'Direct data access' or as 'Public use data files'.

Many of the open data originating from these government sources are republished in supranational open data sources such as those of the World Bank, WHO, UNICEF and many of the donor organisations such as USAID and the Gates Foundation that support the collection of survey data or provide funding for health research in the country.

Both communities and health workers at the facility level can, provided they have the means and the skills to do so, access the HMIS public web portals that provide periodic data at the district level, but not at the level of facility. Using the HMIS web portals requires more than literacy; the portal describes data on the portal using sector-specific jargon and acronyms making it difficult for non-specialists to find and understand the data presented. The portals were also found to be slow and unreliable and contained several incomplete data fields.

Findings from the interviews conducted at the health facilities show that $23(74 \%)$ of the health facility supervisors interviewed were not aware of the government's open health data portals and only 4 (13\%) had made use of the portal in one way or another. Reasons given for using the health portals included accessing health guideline updates, familiarisation with 'hot cases' (disease outbreaks), for reporting and medicine requests and for personal reasons. When asked whether they had ever used other, non-MH data sources (e.g. World Health Organisation, UNICEF), 3 (10\%) respondents indicated that they had used non-government sources, mainly to find new information pertaining to vaccination and disease management.

CSOs indicate that they struggle to access government health data, both at the national level and at the district level. One interviewee indicated that while government welcomes the health system monitoring function performed by her organisation, government also responds to requests for data by saying that it does not want 'our own data to be used to kill us'. There are, however, examples of district health management teams and facilities responding positively to requests for data and express willingness to engage with social accountability monitoring initiatives.

The dLab has been working with health CSOs on the publication of open health data and has made available a data portal to facilitate data publication. To date, hardly any CSOs have made use of the portal. CSOs that receive funding from donors who mandate data sharing as a condition of grants awarded, are publishing anonymised datasets either on the data repository of the funder (e.g. Wellcome Trust and The Bill \& Melinda Gates Foundation) or on an approved data repository (e.g. Harvard Dataverse, Figshare).

The $\mathrm{MH}$ appears to be aware of the disconnect between research and decisionmakers. It has proposed in its most recent policy document (MOHCDGEC 2018) the activation of a National Health Research Forum as a platform for knowledge exchange that will surface regional health priorities. The $\mathrm{MH}$ also commits to an open access policy for research to make research more widely 
accessible. These are both positive steps in integrating research data into the health information system. However, other than to reference a 'Data Dissemination and Use Strategy', the policy remains silent on exactly how research data will be connected to and/or integrated into the health management information system.

Research data and other non-facility health data are not incorporated into the national health management information system. There is also no mechanism for citizen-generated data, such as community-mapped health information, to be captured in any of the central health management information systems. Community reporting could play an important role in upward information flows via the IDSR or other mHealth initiatives so that communities join local and community health workers to create a wider network of disease reporters.

\section{Discussion}

This study has shown that data flows are complex. While empirically valuable, this finding should come as no surprise given the contingency of data flows on social dynamics, that is, on what Bates et al. (2016) refer to as the 'sociomaterial' constitution of data flows. Integrating and connecting flows are not purely technical undertakings but require overcoming socially constructed forces shaped by the distribution of power (the political) and by taken for granted and relatively immutable practices (the institutional).

A clear instance of a socially constructed force and its resultant arrangement of data infrastructures is the number of vertical health programmes in Tanzania defined by international donor agencies. Health programmes for diseases such as TB, malaria and HIV/Aids were siloed within $\mathrm{MH}$ with the support of particular donors and each programme developed its own data infrastructures to monitor and evaluate progress being made in combating its targeted disease. The findings show the remnants of these external interventions but also the progress being made in breaking down divisions between infrastructures (e.g. linking the TB reporting system to dhis2) in order to improve horizontal data flows.

The findings also show that data collection is highly formalised and centralised via the Health Management Information System's dhis2 software around two points in the data system: at the national level (by the $\mathrm{MH}$ ) and at the district level (via the DMOs). The practice of capturing health data on paper combined with multiple instances of transcription slow the upward flow of data and indicate problems related to data quality which, in turn, could constrain data use. In general terms, data use is still relatively weak by virtue of the fact that data practice at all levels is driven by reporting requirements set at various levels of government rather than by the value of data for informed planning and decision-making.

Findings show that data flows are more definitively outwards and upwards from local communities and their health facilities than they are inwards or downwards. There are also several outward and inward data flows that 
terminate. These terminations stagnate the flow of selected health data in the system. Terminations cut off potential feedback loops in the system which, in turn, preclude the possibility of improving on the comprehensiveness and the quality of health data in the system (Piovesan 2017).

A data system with too many breaks and terminations also limits the possibility to improve the relevance of health data for hyperlocal communities. Strong upward flows feeding national-level indicators which are to be used at the regional and local levels for planning and response purposes, lack relevance at the hyperlocal level and more so if local communities are unable to feed into the system data and information directly related to their day-to-day challenges.

Local health facilities and other actors active at the local level in the health system cannot access granular, up to date data on all health facilities via the dhis2. Selected open health data is, however, available on two public web portals, as well as from other government and supranational sources of open health data.

The presence of open health data on national and supranational health portals shifts the focus from the internal flows of health data as described above to the effects of broader, global forces on the flow of data.

There is no coordination between the available open data sources and they are not used by the health facilities, CSOs or other intermediaries serving the local community. This draws attention to the limitations of open data to disrupt data flows determined by the priorities (programmes) of global networks. If data are made openly available but lack value to local communities in the sense that the data is both useful and usable, then open data is unlikely to increase the chances of local community participation in global networks. This finding draws attention to the fact that the digital divide is not solely the product of capacity constraints at the local level but also of the determination of what data is deemed too valuable, what data is collected, who collects and processes it, and how and by whom it is interpreted at supranational and national levels far removed from the needs and interests of local communities.

\section{Conclusion}

The findings of this study on the flow of health data in Tanzania show predominantly unidirectional, upwards and outward flows of data to support the suggested systemic cleavage between hyperlocal communities and globally networked actors. Global health indicators determined at the global level, combined with funding for prioritised health areas, serve to shape national data systems and the flow of data within those systems. Open health data, while clearly available in Tanzania, flows between national and supranational actors but does not initiate new flows of health data to the hyperlocal level.

The findings highlight the need for network switchers, possibly at the local level, who are able to connect the global (the space of flows) with the hyperlocal (the space of places); and for network programmers, possibly at the national 
and supranational levels, who are able to challenge the power of existing global networks as new data flows are activated. Without changes to the current health data system in Tanzania, demand for data at the hyperlocal level will remain poorly defined and thus the flow of data will continue to reflect the needs of those more powerful actors located elsewhere in national networks that are increasingly tied to global networks.

\section{Acknowledgements}

The funding provided by the United States President's Emergency Plan for AIDS Relief (PEPFAR) and the Millennium Challenge Corporation (MCC) via their Data Collaborative for Local Impact (DCLI) programme's DataZetu project is acknowledged, as is the support of the International Development Research Centre (IDRC) and Open Data for Development (OD4D) in the presentation of a draft of this chapter at the Open Data Research Symposium in Buenos Aires in September 2018.

\section{REFERENCES}

Bates J, Lin Y-W \& Goodalde P (2016) Data journeys: Capturing the socio-material constitution of data objects and flows. Big Data E Society: 1-12

Bhatia V, Stout S, Baldwin B \& Homer D (2016) Results Data Initiative: Findings from Tanzania. Washington DC: Development Gateway

Boerma T (2013) Public health information needs in districts. BMC Health Services Research 13 (sup.2): 12. http://www.biomedcentral.com/1472-6963/13/S2/S12

Castells M (1998) End of Millennium. The Information Age: Economy, Society and Culture. Volume 3. Oxford: Blackwell

Castells M (2009) Communication Power. Oxford: Oxford University Press

Castells M (2010) The Rise of the Network Society. The Information Age: Economy, Society and Culture. Volume 1 (revised edition). Oxford: Blackwell

Castells M (2017) Afterword 2017. In: J Muller, N Cloete \& F van Schalkwyk (eds) Castells in Africa: Universities and Development. Cape Town: African Minds. pp. 197-201

Castells M \& Himanen P (2014) Models of development in the global information age: Constructing an analytical framework. In: M Castells \& P Himanen (eds) Reconceptualising Development in the Global Information Age. Oxford: Oxford University Press. pp. 7-25

Custer S, King EM, Atinc TM, Read L \& Sethi T (2018) Toward Data-Driven Education Systems: Insights into using information to measure results and manage change. Brookings Institution and AidData

Data Zetu (2017a, September) Listening campaign guide. https://docs.google.com/ document/d/1lpSr24DrO50bvU1k6qNp5wIPhQ2mTRH0fYOwmNPC7tI/edit

Data Zetu (2017b, 12 October) Pain Points Prioritization Guide: Data Zetu, Kyela. https://docs.google.com/document/d/1GBm5KQVtWzPmqaqdcP3h6CLxDOy_P5QAr8rHFaxKHw/edit?ts=59e811f3\#heading=h.gjdgxs

Dodds L \& Wells P (2019) Issues in open data: Data infrastructure. In: T Davies, S Walker, M Rubinstein \& F Perini (eds) The State of Open Data: Histories and horizons. Cape Town \& Ottawa: African Minds and International Development Research Centre. pp. 260-273 
ECOSOC (2015) Citizen-based Monitoring of Development Cooperation to Support Implementation of the 2030 Agenda. 2016 Development Cooperation Forum Policy Briefs No. 9. New York: Development Cooperation Policy Branch, ECOSOC

Harrison TM, Pardo TA \& Cook M (2012) Creating open government ecosystems: A research and development agenda. Future Internet 4(4): 900-928

Heimstädt M, Saunderson F \& Heath T (2014) From toddler to teen: Growth of an open data ecosystem. JeDem-eJournal of eDemoracy and Open Government 6(2). DOI: https:// doi.org/10.29379/jedem.v6i2.330

Kimunai E (n.d.) Availability of health data. Blog: My One Year of Service - Dodoma, Tanzania. https://myoneyearofservice.wordpress.com/2014/09/16/availability-ofhealth-data/

Kitchin R \& Lauriault TP (2014) Towards critical data studies: Charting and unpacking data assemblages and their work. The Programmable City Working Paper 2. http:// mural.maynoothuniversity.ie/5683/1/KitchinLauriault_CriticalDataStudies_ ProgrammableCity_WorkingPaper2_SSRN-id2474112.pdf

Ministry of Health and Social Welfare, National Aids Control Programme, United Republic of Tanzania (2017, January) National Guidelines on HIV and Aids Data Management. Dar es Salaam: Ministry of Health and Social Welfare

Ministry of Health and Social Welfare, United Republic of Tanzania (2008) Mapping of partners and financial flows in the medicines procurement and supply management system in Tanzania. Dar es Salaam: Ministry of Health and Social Welfare

Ministry of Health and Social Welfare, United Republic of Tanzania (2009) Proposal to Strengthen Health Information System (HIS). Dar es Salaam: Ministry of Health and Social Welfare

Ministry of Health and Social Welfare, United Republic of Tanzania (2015) Health Sector Strategic Plan July 2015-June 2020 (HSSP IV). Dar es Salaam: Ministry of Health and Social Welfare

Ministry of Health, Community Development, Gender, Elderly and Children (MOHCDGEC), United Republic of Tanzania (2016) The National Road Map Strategic Plan to Improve Reproductive, Maternal, Newborn, Child \& Adolescent Health in Tanzania (2016-2020): One Plan II. Dar es Salaam: Ministry of Health, Community Development, Gender, Elderly and Children

Ministry of Health, Community Development, Gender, Elderly and Children (MOHCDGEC), United Republic of Tanzania (2017) The National Health Policy (Sixth Draft Version). Dar es Salaam: Ministry of Health, Community Development, Gender, Elderly and Children

Ministry of Health Community Development, Gender, Elderly and Children, United Republic of Tanzania (2018) Tanzania Health Data Collaborative Communique on Commitments to Support One Monitoring and Evaluation Framework for the Health Sector. Dar es Salaam: Health Data Collaborative

Mori AT, Kaale EA, Ngalesoni F, Norheim OF \& Robberstad B (2014) The role of evidence in the decision-making process of selecting essential medicines in developing countries: The case of Tanzania. PLoS ONE 9(1). DOI 10.1371/journal.pone.0084824

PATH (2017) Journey to Better Data for Better Health in Tanzania 2017-2023. Data Use Partnership. https://www.path.org/resources/data-use-partnership-the-journey-tobetter-data-for-better-health-in-tanzania/

Piovesan F (2017) Beyond standards and regulations: Obstacles to local open government data initiatives in Italy and France. In: F van Schalkwyk, S Verhulst, G Magalhães, J Pane \& J Walker (eds) The Social Dynamics of Open Data. Cape Town: African Minds. pp. 35-62

Ravallion M (2016) Are the world's poorest being left behind? Journal of Economic Growth 21(2): 139-164 
Sato M, Maufi D, Mwingira UJ, Melkizedeck T, Leshabari MT, Ohnishi M \& Honda S (2017) Measuring three aspects of motivation among health workers at primary level health facilities in rural Tanzania. PLoS ONE 12(5). https://doi.org/10.1371/journal. pone. 0176973

Scrollini F (2017) Open your data and will 'they' build it? A case of open data coproduction in health service delivery. In: F van Schalkwyk, S Verhulst, G Magalhães, J Pane \& J Walker (eds) The Social Dynamics of Open Data. Cape Town: African Minds. pp. $139-152$

Silaa R \& Van Schalkwyk F (2018) Mapping Hyperlocal Health Data Flows: The Case of Kyela District, Tanzania. Dar es Salaam: Data Zetu. https://drive.google.com/ file/d/1ESwrmdQYj0rjeQ0_Ws4cbKZMLlk6SQ8Q/view

Tunga M \& Mushi J (2016) Towards engaging civil society organisations (CSOs) in the open data agenda: A case study of selected CSOs in the health sector in Tanzania. Washington DC: World Wide Web Foundation

Unicef (2016) Unicef Annual Report 2016: Tanzania. Unicef. https://www.unicef.org/ about/annualreport/files/Tanzania_(United_Republic_of)_2016_COAR.pdf

United Nations Economic Commission for Africa (ECA) (2017) Africa Data Revolution Report 2016. Addis Ababa: United Nations Economic Commission for Africa

USAID (2015) eLMIS Selection Guide. Arlington, VA: USAID Deliver Project

Van Schalkwyk F \& Cañares M (2020) Open data and social inclusion. In: ML Smith \& RK Seward (eds) Making Open Development Inclusive. Cambridge, MA: MIT Press

Van Schalkwyk F, Verhulst S \& Young A (2017) South Africa's medicine price registry. In: S Verhulst \& A Young (eds) Open Data in Developing Economies: Toward Building an Evidence Base on What Works and How. Cape Town: African Minds. pp. 152-167

Van Schalkwyk F, Willmers M \& McNaughton M (2016) Viscous open data: The roles of intermediaries in an open data ecosystem. Information Technology for Development 22 (sup.1): 68-83. DOI 10.1080/02681102.2015.1081868

Verhulst S \& Young A (eds) (2017) Open Data in Developing Economies: Toward Building an Evidence Base on What Works and How. Cape Town: African Minds

Verhulst S, Noveck B, Caplan R, Brown K \& Paz C (2014) The open data era in health and social care. NYLS Legal Studies Research Paper No. 2563788. Social Sciences Research Network. https://ssrn.com/abstract=2563788 or http://dx.doi.org/10.2139/ ssrn. 2563788

Wickremasinghe D, Hashmi IE, Schellenberg J \& Avan BI (2016) District decisionmaking for health in low income settings: A systematic literature review. Health Policy and Planning 31: ii12-ii24

World Health Organisation (n.d.) Tanzania Country Profile: Health information, research, evidence and knowledge. World Health Organisation (WHO). http://www. aho.afro.who.int/profiles_information/index.php/Tanzania:Health_information,_ research,_evidence_and_knowledge\#Data_sources_and_generation 